\section{National clinical guidelines for management of the palatally ectopic maxillary canine}

\author{
J. Husain, ${ }^{1}$ D. Burden, ${ }^{2}$ P. McSherry, ${ }^{3}$ D. Morris ${ }^{4}$ and M. Allen ${ }^{5}$
}

VERIFIABLE CPD PAPER

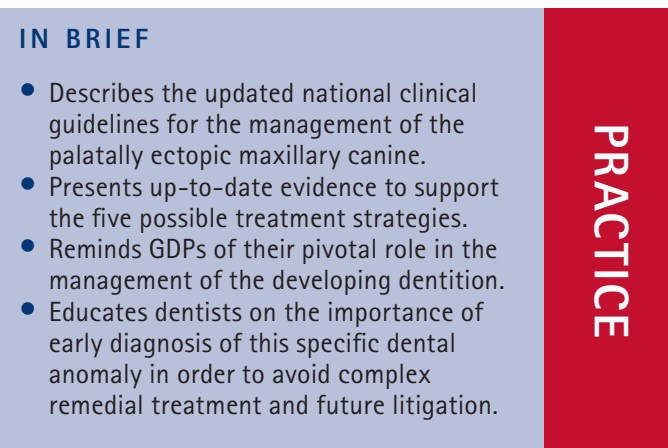

\author{
VERIFIABLE CPD PAPER
}

\begin{abstract}
This review summarises updated clinical guidelines produced by the Clinical Standards Committee of the Faculty of Dental Surgery, Royal College of Surgeons of England (FDSRCS). This guideline on the management of the palatally ectopic maxillary canine illustrates the information contained in the recently updated online version. The timely recognition of ectopic canines is important for the overall management of the dentition. This review illustrates five management strategies for ectopic permanent canines: interceptive treatment by extraction of the deciduous canine, surgical exposure and orthodontic alignment, surgical removal of the palatally ectopic permanent canine, auto-transplantation and no active treatment/ leave and observe. The current available evidence for each of these management options has been evaluated and awarded a grade used by the Scottish Intercollegiate Guidelines Network.
\end{abstract}

\section{INTRODUCTION}

The Royal College of Surgeons of England, Faculty of Dental Surgery (FDSRCS (Eng)) develops and maintains through its Clinical Standards Committee a wide range of clinical guidelines. These are either the work of the committee itself or the endorsement of work by other bodies such as professional societies. This paper reflects the updated guidance produced in 2010 by the FDSRCS (Eng) on the National clinical guidelines for management of the palatally ectopic maxillary canine. ${ }^{1}$ The maxillary permanent canine is second only to the mandibular third molar in its frequency of impaction with a prevalence of about 1.5\%. Ectopic canines occur palatally with more than twice the frequency than they do buccally. ${ }^{2}$ General dental practitioners and orthodontists will commonly encounter this problem and need to be fully aware of managing this situation. Failure to

${ }^{1}$ Consultant Orthodontist, Department of Orthodontics, St. Helens Hospital, Merseyside; ${ }^{2}$ Professor of Orthodontics and Head of Dentistry, Queen's University, Belfast; ${ }^{3}$ Consultant Orthodontist, Health Services Executive, Dublin North East, Ireland; ${ }^{4}$ Head of Orthodontic Department, ${ }^{5}$ Orthodontic StR, Orthodontic Department, Leeds Dental Institute, Leeds

${ }^{*}$ Correspondence to: Dr David Morris

Email: desk@domorris.plus.com

\section{Refereed Paper}

Accepted 25 May 2012

DOI: $10.1038 /$ sj.bdj.2012.726

${ }^{\circledR}$ British Dental Journal 2012; 213: 171-176 diagnose and manage the ectopic upper canine efficiently can result in more complex remedial treatment becoming necessary, which would be costly in terms of clinical time for both the practitioner and patient. There is also the risk of damage occurring to adjacent teeth, which may lead to costly litigation claims.

The aetiology of the palatal canine ectopia remains unclear, but a possible genetic effect has been proposed. ${ }^{3}$ There is evidence that palatally ectopic canines occur more frequently than expected among family members. There may also be an association $^{4,5}$ with absent, malformed or diminutive lateral incisors, ${ }^{6}$ an absence of crowding and late developing dentitions. ${ }^{7}$ The majority of canines undergoing normal eruption should be palpable in the buccal sulcus by $10-11$ years of age. ${ }^{8}$ Those maxillary canines erupting after approximately 12.3 years in girls and 13.1 years in boys may be considered late. ${ }^{9}$

The main risk from ectopia appears to be root resorption of adjacent teeth, usually the incisors. It has been estimated that $0.6-0.8 \%$ of children in the $10-13$ year age group have permanent incisors resorbed as a result of canine ectopia. ${ }^{2}$ However, cone-beam computed tomography (CT) scanning has detected root resorption in $66.7 \%$ of permanent lateral incisors adjacent to ectopic maxillary canines. ${ }^{10}$
It has been stated that root resorption of incisors by palatally ectopic canines rarely starts after 14 years of age ${ }^{11}$ and it occurs most frequently between 11 and 12 years. ${ }^{12}$

Other possible sequelae of canine ectopia are resorption of the coronal aspect of the root, which is most likely to occur in adults, with quoted frequencies of up to $14 \% 0^{13}$ and cystic changes - the frequency of which is generally thought to be low. ${ }^{14}$

\section{DIAGNOSIS AND MANAGEMENT}

\section{History and examination}

Practitioners should suspect ectopia if the canine is not palpable in the buccal sulcus by the age of 10-11 years, if palpation indicates an asymmetrical eruption pattern or the position of adjacent teeth implies a malposition of the permanent canine. The patient with an ectopic maxillary canine must undergo a comprehensive assessment of the malocclusion, including accurate localisation of the canine.

\section{Radiographic examination ${ }^{15-17}$}

Radiographic procedures before the age of 10-11 years are usually of little benefit in terms of the knowledge gained. ${ }^{2,8}$

The examination usually involves taking two radiographs and using the principle of horizontal or vertical ${ }^{18}$ parallax. 


\section{PRACTICE}

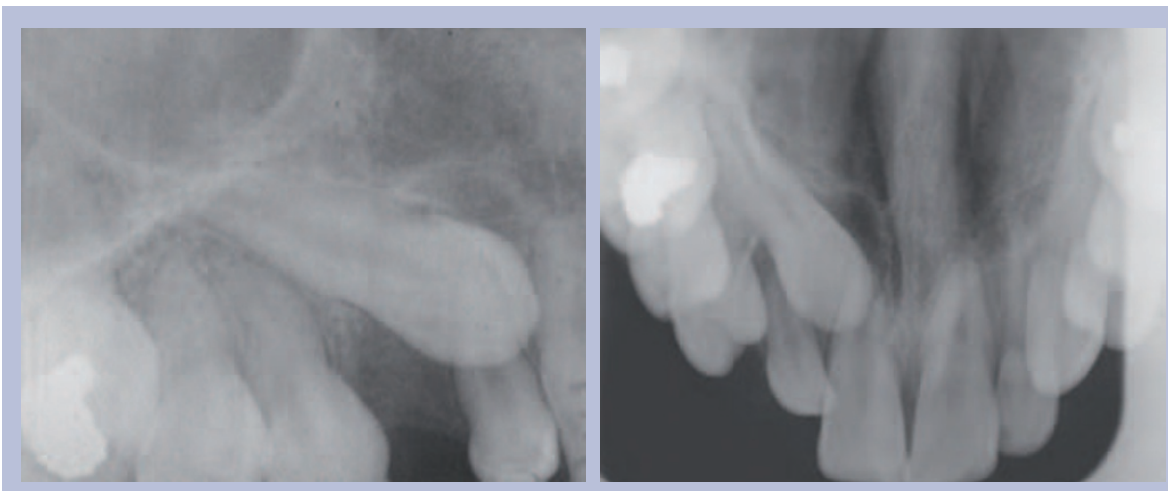

Fig. 1 A periapical radiograph and an upper anterior occlusal radiograph demonstrating horizontal parallax in determining the location of the upper right permanent canine

Recent research has shown that the horizontal parallax technique is more reliable than vertical parallax in localising unerupted canines. ${ }^{19}$

\section{Horizontal parallax}

1. Anterior occlusal and periapical (Fig. 1)

2. Two periapicals (Fig. 2).

\section{Vertical parallax}

1. Anterior occlusal (70-75 $)$ and dental panoramic tomograms (DPT) (Fig. 3)

2. Periapical and DPT (Fig. 4).

More recently, cone beam CT technology has become available for imaging the maxillofacial region and this can be used for the localisation of impacted teeth, including

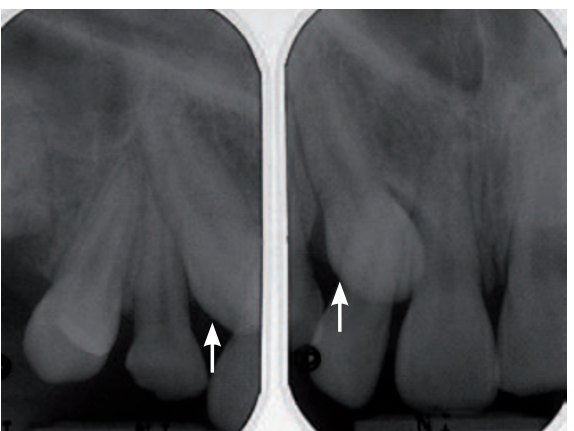

Fig. 2 Two periapical radiographs demonstrating horizontal parallax in determining the location of the upper left permanent canine

canines. ${ }^{10}$ This technique allows highly accurate localisation of the impacted tooth and visualisation of associated structures. However, it is associated with a higher overall effective dose than conventional radiography and currently there are no formal referral criteria with regard to its use in the United Kingdom and its routine use is not considered justified in orthodontics ${ }^{15}$ (Fig. 5).

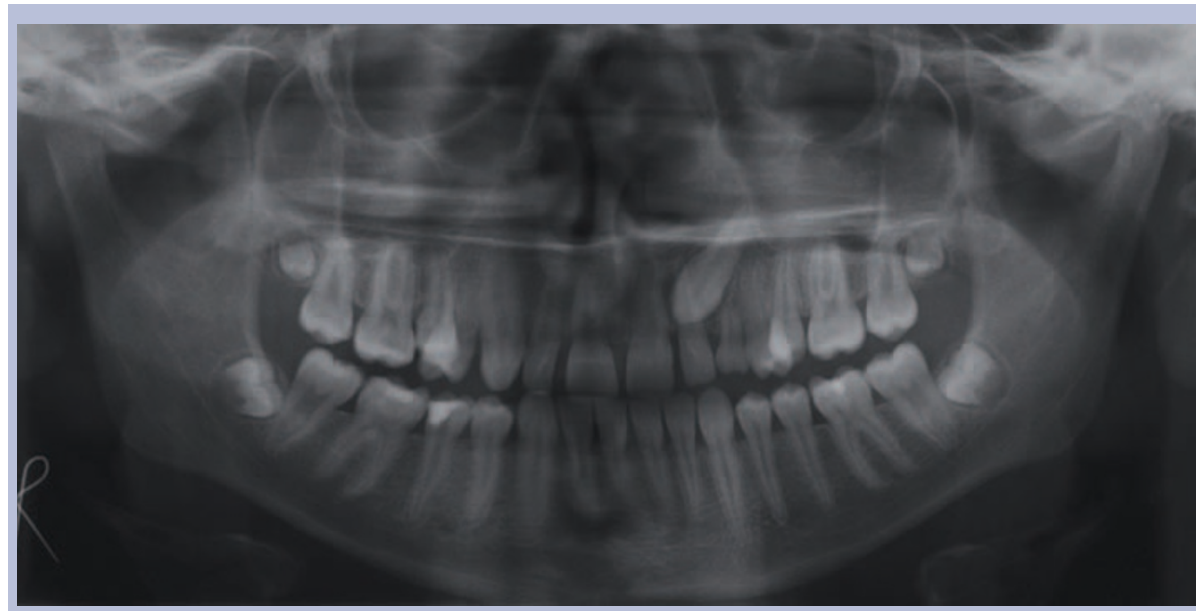

Fig. 3 A DPT and an upper anterior occlusal demonstrating vertical parallax for the localisation of the upper left permanent canine
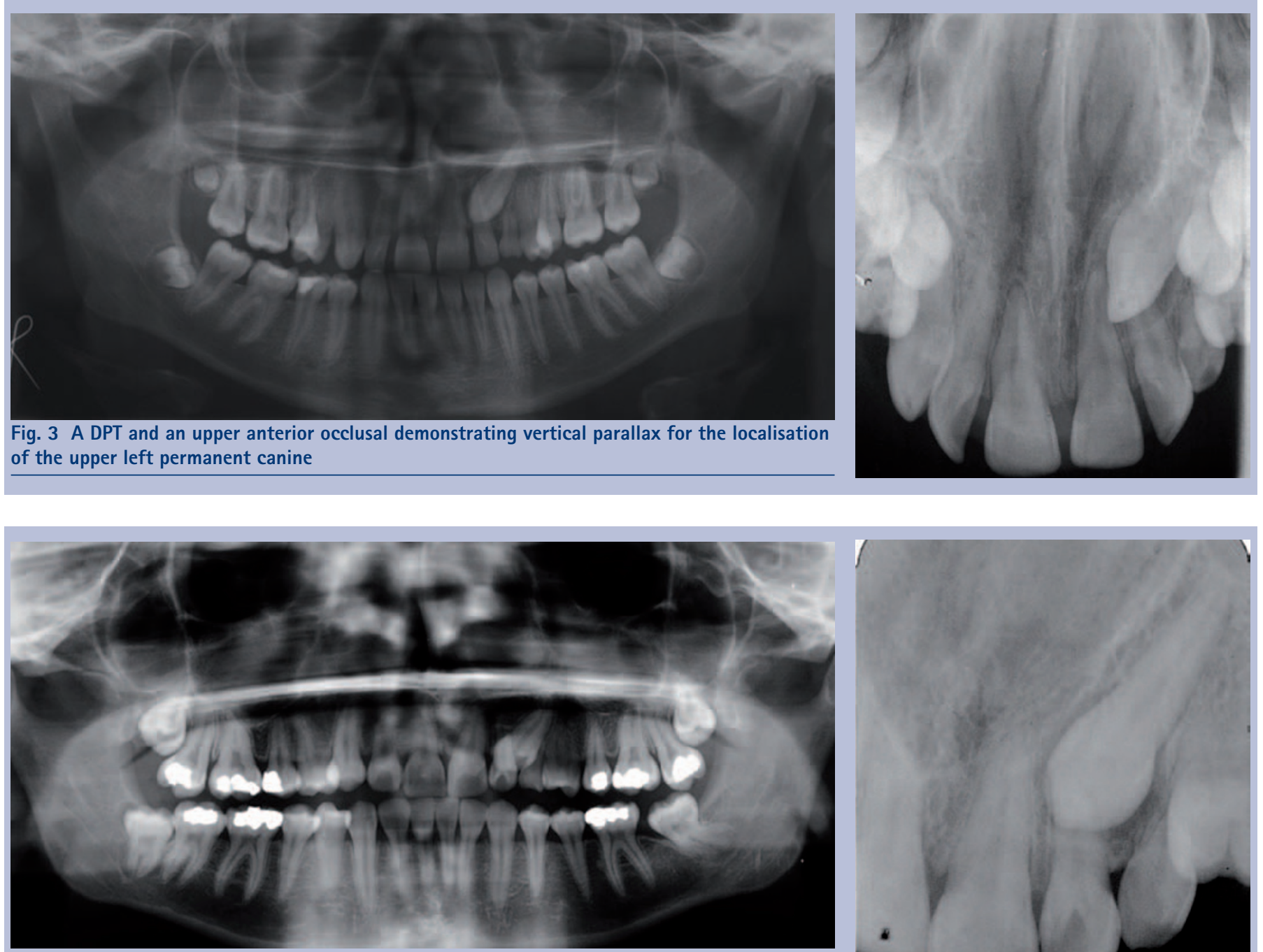

Fig. 4 A DPT and a periapical radiograph demonstrating vertical parallax for the localisation of the upper left permanent canine

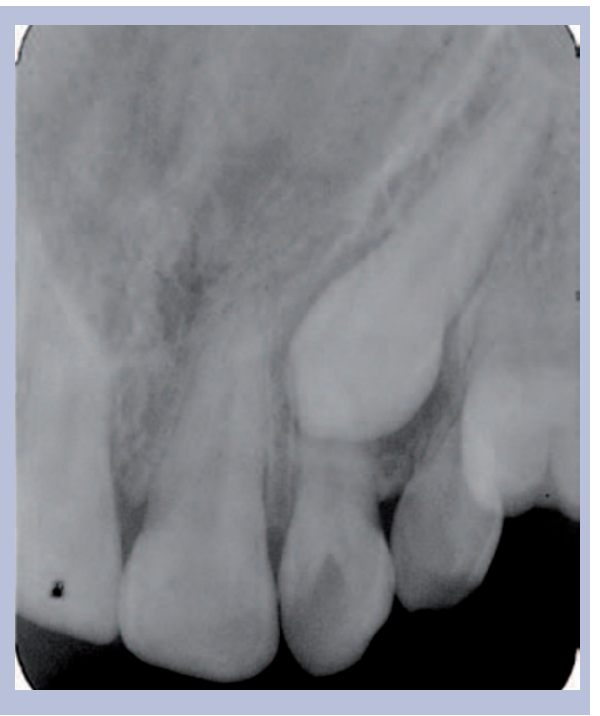




\begin{tabular}{|c|c|}
\hline Grade & Description \\
\hline A & $\begin{array}{l}\text { Requires at least one randomised controlled trial as part of a body of literature of overall } \\
\text { good quality and consistency addressing the specific recommendation. }\end{array}$ \\
\hline B & $\begin{array}{l}\text { Requires the availability of well-conducted clinical studies but no randomised clinical trials } \\
\text { on the topic of recommendation. }\end{array}$ \\
\hline C & $\begin{array}{l}\text { Requires evidence obtained from expert committee reports or opinions and/or clinical } \\
\text { experiences of respected authorities. Indicates an absence of directly applicable clinical } \\
\text { studies of good quality. }\end{array}$ \\
\hline
\end{tabular}

\section{TREATMENT}

Radiographic examination should be carried out initially to confirm the position of the unerupted canine. Patient and parent counselling on the various treatment options is essential. Treatment planning for patients with palatally ectopic maxillary canines is not straightforward due to the large number of patient factors and orthodontic considerations, which must be taken into account. It is strongly recommended that less experienced practitioners seek the opinion of an orthodontic specialist before initiating any of the following treatment options. The best available evidence for each option described has been assigned a grade (Table 1), in accordance with the Scottish Intercollegiate Guidelines Network (SIGN) grading scheme (www.sign.ac.uk).

\section{Interceptive treatment by extraction of the deciduous canine (SIGN Grade A)}

Clinical inspection and buccal palpation of the alveolus in the canine region are recommended annually from the age of eight years. Initial research appeared to indicate that the interceptive isolated extraction of the associated deciduous canine, if successful, was a very cost-effective and simple method of correcting canine ectopia. ${ }^{20}$ This original study found that $78 \%$ of palatally ectopic canines reverted to a normal path of eruption following the extraction of the primary canine, although success appeared to reduce as the degree of malposition increased. A later investigation appeared to confirm this finding, although the success rate was found to be slightly lower (62\%). ${ }^{21}$ Subsequently, in a longitudinal prospective study of this interceptive technique, ${ }^{22}$ it was found that successful permanent canine eruption occurred in 36\% of cases in the untreated control group but 65.2\% of cases that had had isolated extraction of the deciduous canine, which was statistically significant. Interestingly, when (cervical pull) headgear was used, along with extraction of the deciduous canine, the success rate increased to $87.5 \%$.

A recent systematic review found that no clinical trials currently available adequately met the inclusion criteria required for the review and as a result, it was concluded that there was currently no scientifically robust evidence to support the extraction of the deciduous maxillary canine to facilitate the eruption of the permanent successor. ${ }^{23}$ Further well-reported randomised controlled trials are required to assess the full effectiveness of this clinical intervention.

In selected cases, there is some evidence that interceptive extraction of a retained deciduous canine can result in an improvement in the position of an ectopic permanent canine (Fig. 6).
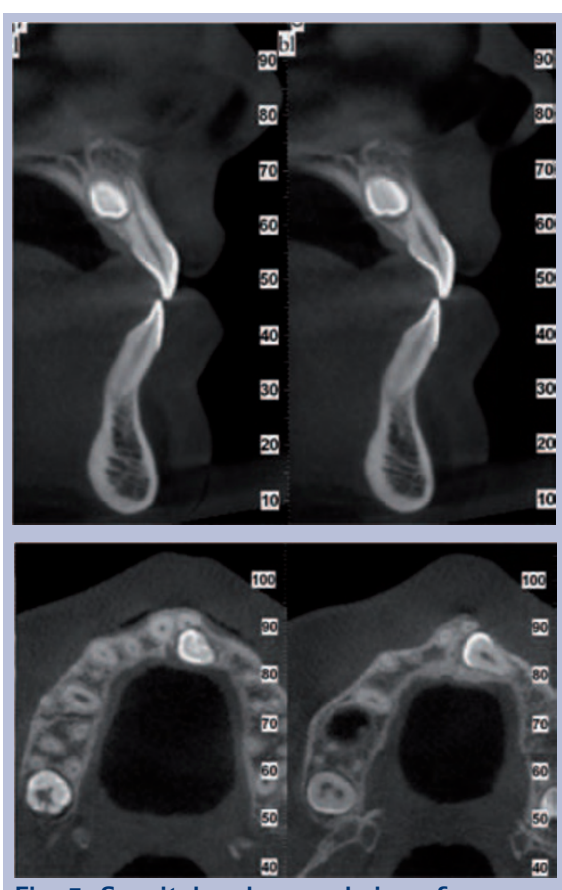

Fig. 5 Saggital and coronal views from cone beam CT demonstrating root resorption by the palatally ectopic upper right permanent canine

Factors which determine whether to consider providing interceptive treatment by removal of the deciduous canine are as follows:

- The patient should be aged between 10-13 years, with better results reported in the absence of crowding

- The need to space maintain (or even create additional space), requires consideration

- If radiographic examination reveals no improvement in the ectopic canine's position 12 months after extraction of the deciduous canine, alternative treatments should be considered.

\section{Surgical exposure and orthodontic alignment (SIGN Grade C)}

Much of the evidence supporting surgical exposure and orthodontic alignment as a treatment approach is derived from case
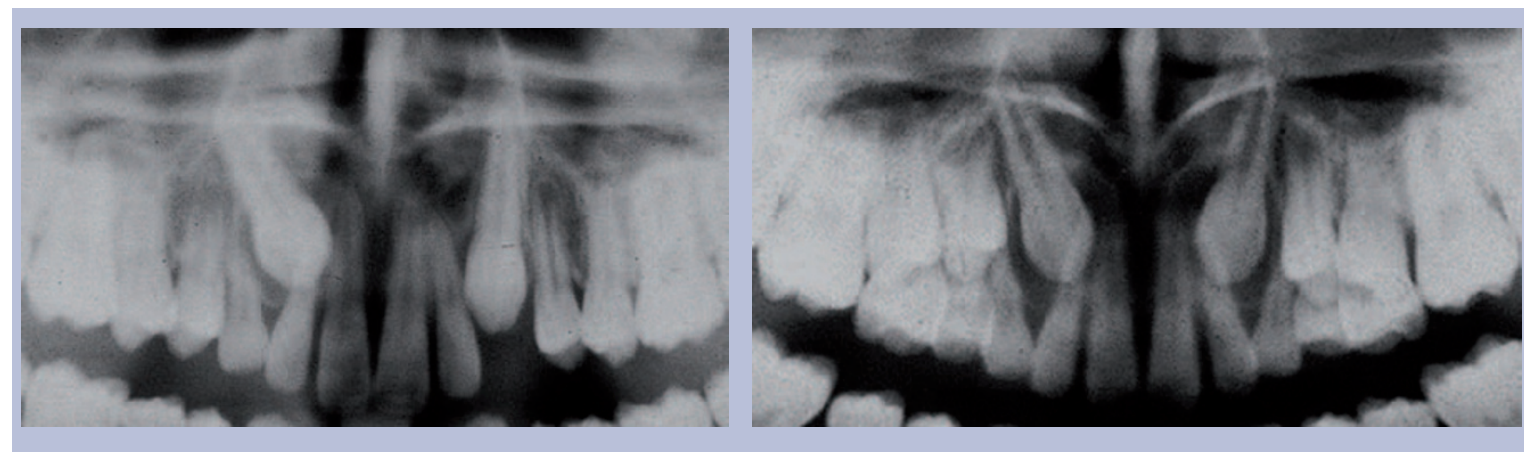

Fig. 6 Sectional DPTs demonstrating improvement in the position of the upper left permanent canine after removal of the upper left deciduous canine 


\section{PRACTICE}
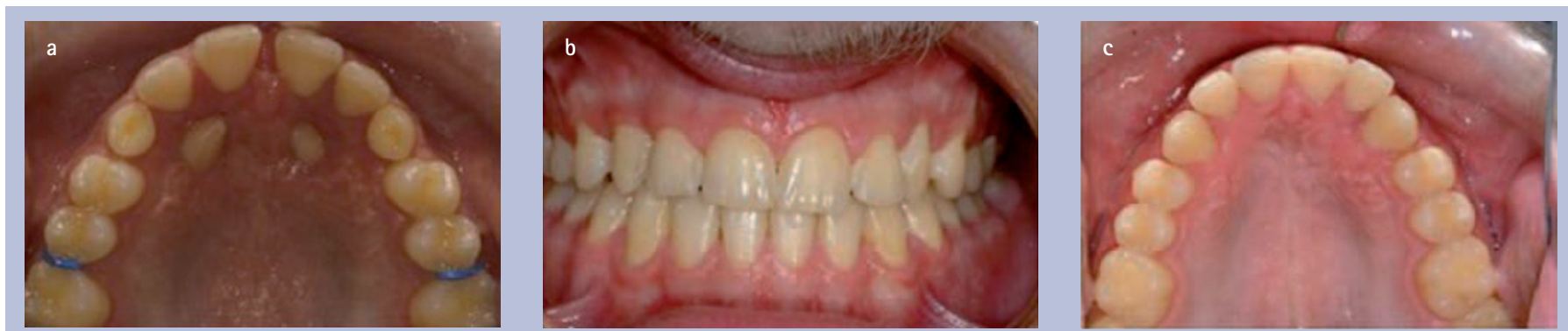

Fig. 7 (a) Occlusal photograph taken after exposure of both palatally impacted canines. (b) and (c) Successful alignment of the palatally impacted canines after fixed orthodontic appliance treatment.

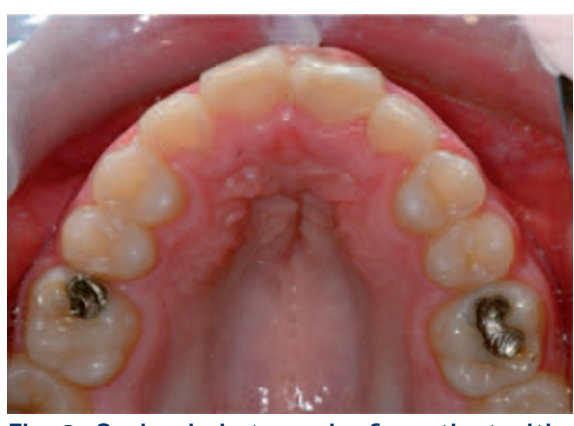

Fig. 8 Occlusal photograph of a patient with missing maxillary canines demonstrating good contact between the first premolar and lateral incisor teeth bilaterally

studies (Fig. 7). However, clinical experience has shown that surgical exposure and orthodontic alignment of a palatally ectopic canine can be a highly successful treatment approach. As with all orthodontic treatment, the cooperation and motivation of the patient is paramount. The general dental health should be good since the treatment time is often prolonged. When comparing open versus closed exposure techniques, some authors ${ }^{24}$ consider that the available evidence favours the latter approach, while others have reported that there is no evidence to show that subsequent periodontal health is better with either one, although repeat surgery is more common with the closed exposure technique. ${ }^{25}$ Currently, there is no clear evidence to support one surgical technique over the other in terms of dental health, aesthetics, economics and patient factors. ${ }^{26}$ However, it is generally agreed that the optimal time for surgical exposure and orthodontic alignment is during adolescence. ${ }^{27-29}$

Factors which determine whether to consider surgically exposing and orthodontically aligning the ectopic permanent canine are as follows:

- The case is not considered to be suitable for interceptive extraction of the deciduous canine

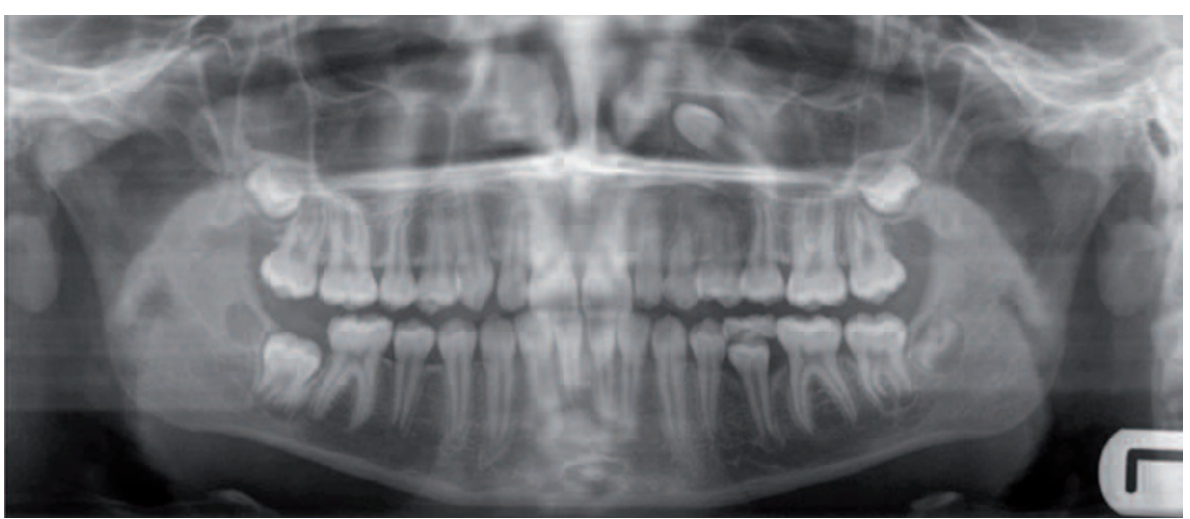

Fig. 9 A DPT demonstrating a severely ectopic upper left permanent canine

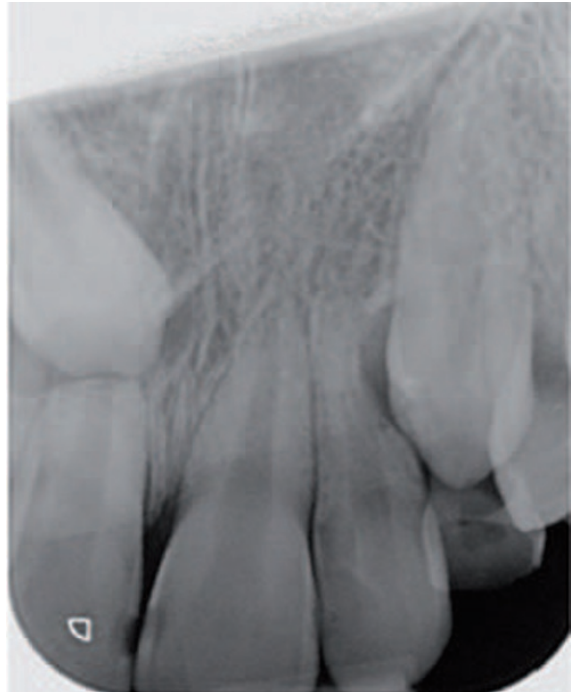

Fig. 10 Periapical radiograph demonstrating early root resorption of the upper left lateral incisor root by the erupting canine

- The patient should be willing to wear fixed orthodontic appliances

- The patient should be well motivated and have good dental health

- The degree of malposition of the ectopic canine should not be so great that orthodontic alignment is impractical (for example, close proximity to the midline, above the apices of the adjacent teeth, horizontal angulation).

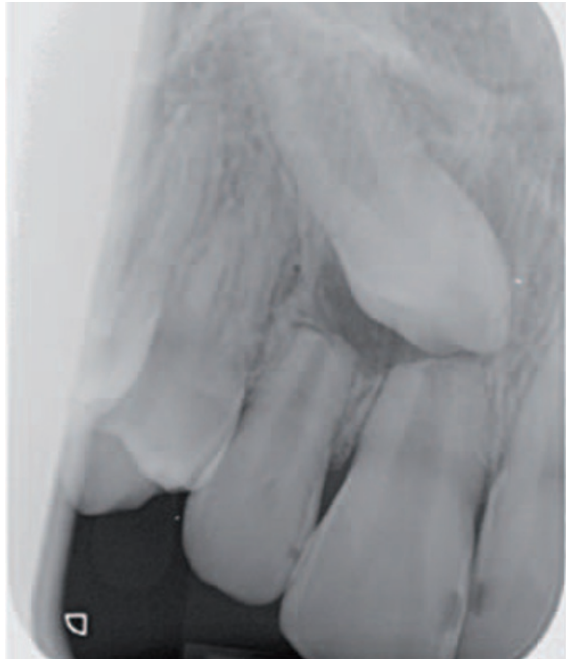

Fig. 11 Periapical radiograph demonstrating severe root resorption of both the upper right lateral and central incisor roots by the erupting canine

\section{Surgical removal of the palatally ectopic permanent canine (SIGN Grade C)}

Surgical removal of the ectopic canine is most often considered when dental aesthetics are acceptable with good contact between the lateral incisor and the first premolar (Fig. 8). It is also considered when the canine is severely malpositioned (Fig. 9), when alignment and transplantation is not being considered and in cases where there are pathological changes and/ 


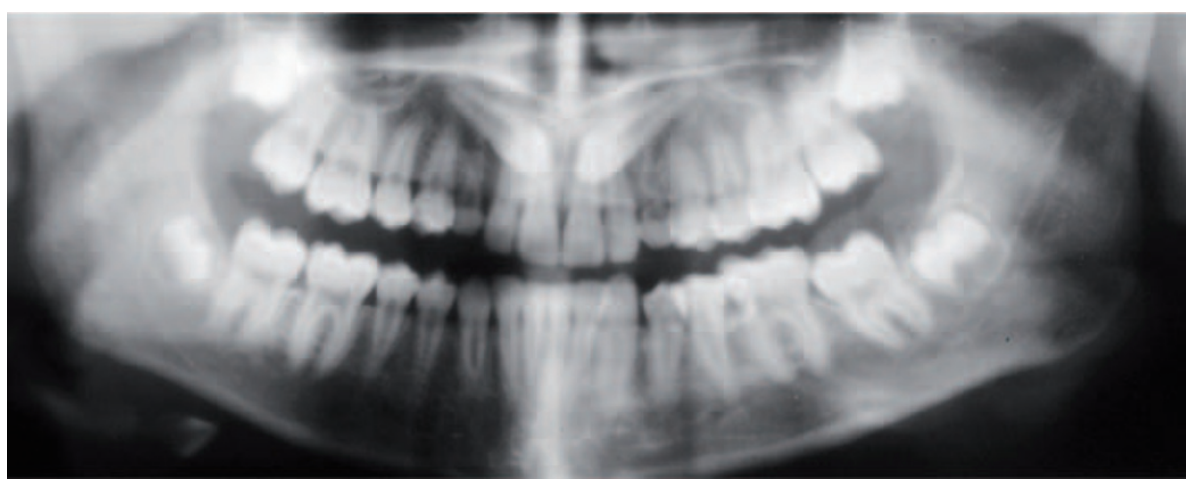

Fig. 12a A DPT showing the position of ectopic maxillary canines prior to transplantation

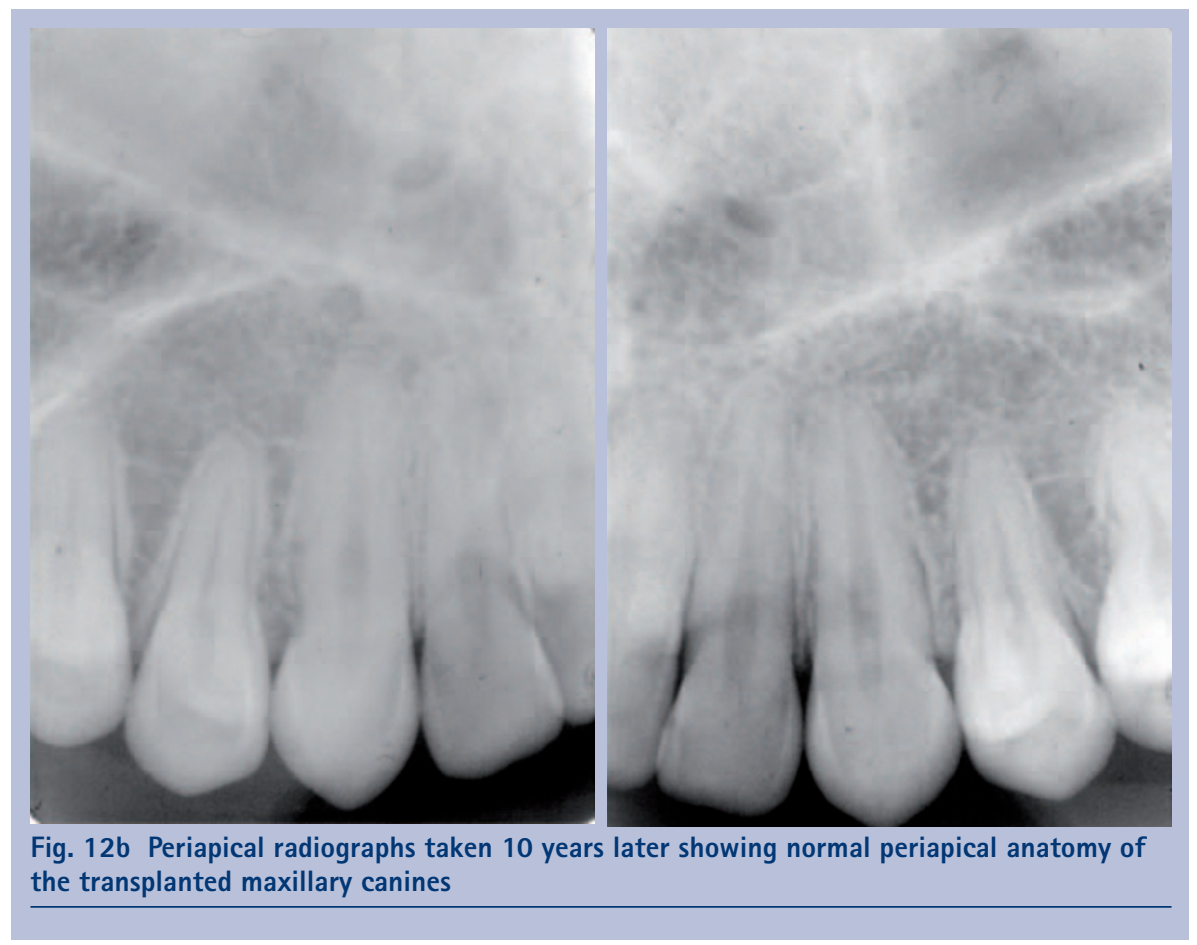

or its retention would impede orthodontic tooth movement. If necessary, fixed orthodontic appliances can be used to bring the first premolar forward to simulate a canine tooth: mesio-palatal rotation of the premolar, placement of buccal root torque and/ or grinding of the palatal cusp, can also help to improve aesthetics. Clinical experience would indicate that there is a large variation in the life-expectancy of retained deciduous canines.

Factors which determine whether to consider surgically removing the ectopic permanent canine are as follows:

- This treatment option should be considered if the patient declines active treatment and/or is happy with their dental appearance

- Surgical removal of the ectopic canine should be considered if there is radiographic evidence of early root resorption (Fig. 10) of the adjacent incisor teeth (but exposure and alignment of the ectopic canine is usually indicated in cases where severe root resorption of an incisor tooth has occurred necessitating the extraction of the incisor) (Fig. 11)

- The best results are achieved if there is good contact between the lateral incisor and first premolar (Fig. 8) or the patient is willing to undergo orthodontic treatment to substitute the first premolar for the canine

- The possible risk of damaging the roots of adjacent teeth during the act of surgically removing the impacted canine should be assessed and discussed with the patient.

\section{Transplantation (SIGN Grade B)}

Transplantation ${ }^{30-33}$ is sometimes considered for grossly displaced ectopic maxillary canines or when prolonged orthodontic treatment is unacceptable to the patient. Early studies revealed disappointing long-term results when this approach was adopted with a high frequency of root resorption occurring. More recent studies using a meticulous atraumatic surgical technique and stabilisation of the transplanted tooth with a sectional archwire for six weeks have reported better results. ${ }^{33}$ However, the long-term ( $>5$ years) prognosis of transplanted palatally ectopic canines has yet to be evaluated, although for other teeth it can be as high as 90\%. ${ }^{31,32}$ Factors which determine whether to consider transplanting the ectopic permanent canine are as follows:

- Transplantation is not normally considered unless other possible active (or interceptive) treatment has failed or is felt to be inappropriate

- This treatment option can be considered if the patient is unwilling to wear orthodontic appliances or the degree of malposition is too great for orthodontic alignment to be practical (Fig. 12a)

- There should be adequate space available for the canine and sufficient alveolar bone to accept the transplanted tooth

- The prognosis should be good for the canine tooth to be transplanted (Fig. 12b) with no evidence of ankylosis. The best results are achieved if the ectopic canine can be removed with minimal trauma

- Depending on the stage of root formation (that is, $>3 / 4$ root formed), the transplanted canine may require root canal therapy to be commenced within 10 days following transplantation.

\section{No active treatment/leave and observe (SIGN Grade C)}

Factors which determine whether to consider this option for the ectopic permanent canine are as follows:

- The patient does not want treatment or is happy with their dental appearance

- There should be no evidence of root resorption of adjacent teeth or other pathology

- Ideally, there should be good contact between the lateral incisor and first premolar or the deciduous canine should have a good prognosis 
- Severely displaced palatally ectopic canines with no evidence of pathology may be left in-situ, particularly if the canine is remote from the dentition. If the ectopic canine is left in-situ, then, as with any unerupted tooth, the practitioner providing continuing care for the patient should carry out a careful clinical examination of the patient on a regular basis to ensure the unerupted canine does not represent a risk to the patient's well-being. No guidance currently exists as to how frequently radiographic checks should be carried out.

The authors would like to thank Dr Mary Short (Consultant Orthodontist, Bournemouth) for providing the images in Figure 6.

1. Husain J, Burden D, McSherry P. Management of the palatally ectopic maxillary canine. London: The Royal College of Surgeons of England, Faculty of Dental Surgery, 2010. Online article available at http://www.rcseng.ac.uk/fds/publications-clinicalguidelines/clinical guidelines/index.html (accessed August 2012)

2. Ericson S, Kurol J. Radiographic examination of ectopically erupting maxillary canines. Am J Orthod Dentofacial Orthop 1987: 91: 483-492.

3. Peck S, Peck L, Kataja M. The palatally displaced canine as a dental anomaly of genetic origin. Angle Orthod 1994; 64: 249-256.

4. Peck S, Peck L, Kataja M. Concomitant occurrence of canine malposition and tooth agenesis: evidence of orofacial genetic fields. Am J Orthod Dentofacial Orthop 2002; 122: 657-660.

5. Zilberman Y, Cohen B, Becker A. Familial trends in palatal canines, anomalous lateral incisors and related phenomena. Eur J Orthod 1990; 12: 135-139.

6. Brin I, Becker A, Shalhav M. Position of the maxillary permanent canine in relation to anomalous or missing lateral incisors: a population study. Eur J Orthod 1986; 8: 12-16.

7. Chaushu S, Sharabi S, Becker A. Dental morphologic characteristics of normal versus delayed developing dentitions with palatally displaced canines. Am J Orthod Dentofacial Orthop 2002: 121: 339-346.

8. Ericson $\mathrm{S}, \mathrm{Kurol}$ J. Longitudinal study and analysis of clinical supervision of maxillary canine eruption. Community Dent Oral Epidemiol 1986; 14: 172-176.

9. Hurme $V 0$. Ranges of normalcy in the eruption of permanent teeth. J Dent Child 1949; 16: 11-15.

10. Walker L, Enciso R, Mah J. Three-dimensional localization of maxillary canines with cone-beam computed tomography. Am J Orthod Dentofacial Orthop 2005; 128: 418-423.

11. Houston W J B, Stephens C D, Tulley W J. A textbook of orthodontics. Bristol: John Wright, 1992.

12. Ericson $\mathrm{S}, \mathrm{Kurol} J$. Resorption of maxillary lateral incisors caused by ectopic eruption of the canines. A clinical and radiographic analysis of predisposing factors. Am J Orthod Dentofacial Orthop 1988; 94: 503-513.

13. Azaz B, Shteyer A. Resorption of the crown in impacted maxillary canine. A clinical, radiographic and histologic study. Int J Oral Surg 1978; 7: 167-171.

14. Mourshed F. A roentogenographic study of dentigerous cysts I. Incidence in a population sample. Oral Surg Oral Med Oral Pathol 1964; 18: 47-53.

15. Isaacson K G, Thom A R, Horner K, Whaites E. Orthodontic Radiographs Guidelines. 3rd ed. London: British Orthodontic Society, 2008.

16. Mason C, Papadakou P, Roberts G J. The radiographic localization of impacted maxillary canines: a comparison of methods. Eur J Orthod 2001; 23: 25-34.

17. Jacobs S G. Localization of the unerupted maxillary canine: how to and when to. Am J Orthod Dentofacial Orthop 1999; 115: 314-322.

18. Southall P J, Gravely J F. Vertical parallax radiology to localize an object in the anterior part of the maxilla. Br J Orthod 1989; 16: 79-83

19. Armstrong $C$, Johnston $C$, Burden $D$, Stevenson M. Localizing ectopic maxillary canines - horizontal or vertical parallax? Eur J Orthod 2003; 25: 585-589.

20. Ericson S, Kurol J. Early treatment of palatally erupting maxillary canines by extraction of the primary canines. Eur J Orthod 1988; 10: 283-295.
21. Power S M, Short M B. An investigation into the response of palatally displaced canines to the removal of deciduous canines and an assessment of factors contributing to favourable eruption. $\mathrm{Br} J$ Orthod 1993; 20: 215-223.

22. Baccetti $T$, Leonardi M, Armi P. A randomized clinical study of two interceptive approaches to palatally displaced canines. Eur J Orthod 2008; 30: 381-385.

23. Parkin N, Benson P E, Shah A et al. Extraction of primary (baby) teeth for unerupted palatally displaced permanent canine teeth in children. Cochrane Database Syst Rev 2009; 2: CD004621.

24. Becker A. The orthodontic treatment of impacted teeth. Oxford. Informa UK Ltd, 2007.

25. Burden D J, Mullally B H, Robinson S N. Palatally ectopic canines: closed eruption versus open eruption. Am J Orthod Dentofacial Orthop 1999; 115: 640-644.

26. Parkin N, Benson P E, Thind B, Shah A. Open versus closed surgical exposure of canine teeth that are displaced in the roof of the mouth. Cochrane Database Syst Rev 2008; 4: CD006966.

27. Galloway I, Stirrups D R. The effect of age at diagnosis on the complexity and treatment of palatally ectopic canines. Br J Orthod 1989; 16: 259-263.

28. Altonen M, Myllärniemi S. Results of surgical exposure of impacted cuspids and bicuspids in relation to patients' somatic and dental maturation. In J Oral Surg 1976; 5: 180-186.

29. Stewart J A, Heo G, Glover K E, Williamson P C, Lam E W, Major P W. Factors that relate to treatment duration for patients with palatally impacted maxillary canines. Am J Orthod Dentofacial Orthop 2001; 119: 216-225.

30. Thomas S, Turner S R, Sandy J R. Autotransplantation of teeth: Is there a role? $\mathrm{Br} J$ Orthod 1998; 25: 275-282.

31. Czochrowska E M, Stenvik A, Bjercke B, Zachrisson $B$ U. Outcome of tooth transplantation: survival and success rates $17-41$ years post treatment. Am J Orthod Dentofacial Orthop 2002; 121: 110-119.

32. Andreasen J O, Paulsen HU, YU Z, Ahlquist R, Bayer T, Schwartz O. A long term study of 370 autotransplanted premolars. Parts I-IV. Eur J Orthod 1990; 12: $3-50$.

33. Sagne $\mathrm{S}$, Thilander B. Transalveolar transplantation of maxillary canines. A critical evaluation of a clinical procedure. Acta Odontol Scand 1997; 55: 1-8. 